\title{
A Shared Pattern of $\beta$-Catenin Activation in Bronchopulmonary Dysplasia and Idiopathic Pulmonary Fibrosis
}

\author{
Jennifer M.S. Sucre, ${ }^{*}$ Gail H. Deutsch, ${ }^{\dagger}$ Christopher S. Jetter, ${ }^{*}$ Namasivayam Ambalavanan,${ }^{\ddagger}$ John T. Benjamin, \\ Linda A. Gleaves, ${ }^{\S}$ Bryan A. Millis, ${ }^{\mathbb{q} \| * *}$ Lisa R. Young, ${ }^{\S \Phi \dagger \dagger}$ Timothy S. Blackwell, ${ }^{\S \dagger \dagger t \ddagger £ \S}$ Jonathan A. Kropski, ${ }^{\S}$ and
} Susan H. Guttentag*

\begin{abstract}
From the Mildred Stahlman Division of Neonatology, * Department of Pediatrics, the Department of Cell and Developmental Biology, ${ }^{\boldsymbol{1}}$ the Cell Imaging Shared Resource," and the Vanderbilt Biophotonics Center, ${ }^{* *}$ Vanderbilt University, Nashville, Tennessee; the Department of Pathology, ${ }^{\dagger}$ Seattle Children's Hospital and University of Washington, Seattle, Washington; the Department of Pediatrics, ${ }^{\ddagger}$ University of Alabama at Birmingham, Birmingham, Alabama; the Division of Allergy, Pulmonary and Critical Care Medicine, ${ }^{\S}$ Department of Medicine, the Division of Pulmonary Medicine, ${ }^{\dagger \dagger}$ Department of Pediatrics, and the Department of Cancer Biology, ${ }^{\ddagger \ddagger}$ Vanderbilt University Medical Center, Nashville, Tennessee; and the Nashville Veterans Affairs Medical Center, ${ }^{\S \S}$ Nashville, Tennessee
\end{abstract}

Accepted for publication

December 5, 2017.

Address correspondence to Jennifer M.S. Sucre, M.D., Vanderbilt University, 2215B Garland Ave, 1125 Light Hall, Nashville, TN 37232. E-mail: jennifer.sucre@vanderbilt.edu.

\begin{abstract}
Wnt/ $\beta$-catenin signaling is necessary for normal lung development, and abnormal Wnt signaling contributes to the pathogenesis of both bronchopulmonary dysplasia (BPD) and idiopathic pulmonary fibrosis (IPF), fibrotic lung diseases that occur during infancy and aging, respectively. Using a library of human normal and diseased human lung samples, we identified a distinct signature of nuclear accumulation of $\beta$-catenin phosphorylated at tyrosine 489 and epithelial cell cytosolic localization of $\beta$-catenin phosphorylated at tyrosine 654 in early normal lung development and fibrotic lung diseases BPD and IPF. Furthermore, this signature was recapitulated in murine models of BPD and IPF. Image analysis of immunofluorescence colocalization demonstrated a consistent pattern of elevated nuclear phosphorylated $\beta$-catenin in the lung epithelium and surrounding mesenchyme in BPD and IPF, closely resembling the pattern observed in 18week fetal lung. Nuclear $\beta$-catenin phosphorylated at tyrosine 489 associated with an increased expression of Wnt target gene AXIN2, suggesting that the observed $\beta$-catenin signature is of functional significance during normal development and injury repair. The association of specific modifications of $\beta$-catenin during normal lung development and again in response to lung injury supports the widely held concept that repair of lung injury involves the recapitulation of developmental programs. Furthermore, these observations suggest that $\beta$-catenin phosphorylation has potential as a therapeutic target for the treatment and prevention of both BPD and IPF. (Am J Pathol 2018, 188: 853-862; https://doi.org/10.1016/j.ajpath.2017.12.004)
\end{abstract}

Bronchopulmonary dysplasia (BPD) and idiopathic pulmonary fibrosis (IPF) are chronic fibrotic lung diseases that occur at opposite ends of the human developmental spectrum, with BPD affecting mostly preterm neonates and IPF presenting in adults during or after their sixth decade of life. ${ }^{1,2}$ Despite distinct epidemiology, there is growing

\footnotetext{
Supported by NIH grant K12 HD087023 (J.M.S.S.); National Institute of General Medical Sciences grant GM108807 (S.H.G.); National Heart, Lung, and Blood Institute grants K08HL133484 (J.T.B.), R01HL119503 (L.R.Y.), K08HL130595 (J.A.K.), P01HL92870 (T.S.B.), and R01HL085317 (T.S.B.); Department of Veterans Affairs grant BX002378 (T.S.B.); the Francis Family Foundation (J.A.K.); the Pulmonary Fibrosis Foundation (J.A.K.); and the Julia Carrell Stadler Chair in Pediatrics (S.H.G.). Experiments were performed, in part, through the use of the
}

Vanderbilt University Cell Imaging Shared Resource, supported by NIH grants CA68485, DK20593, DK58404, and DK5963.

J.A.K. and S.H.G. contributed equally as senior authors.

Disclosures: None declared.

A guest editor acted as the Editor-in-Chief for this manuscript. No person at the University of Alabama at Birmingham was involved in the peer review process or final disposition of this article. 
A
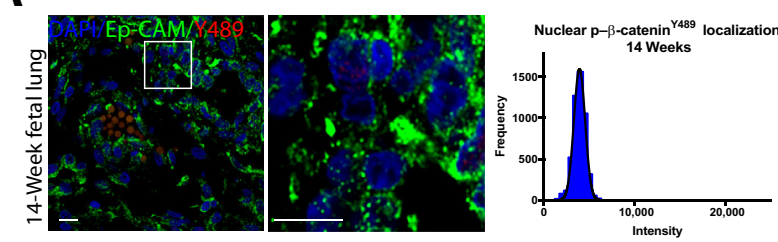

C
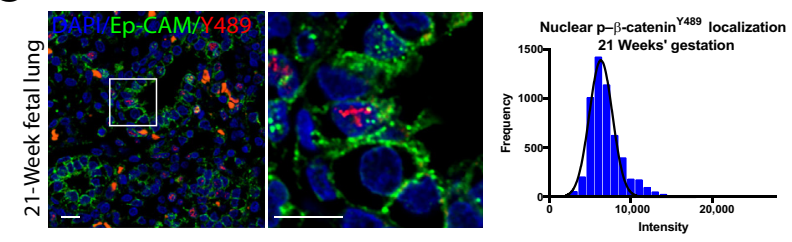

E
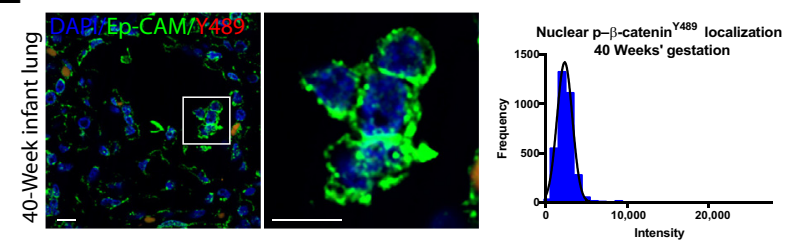

B
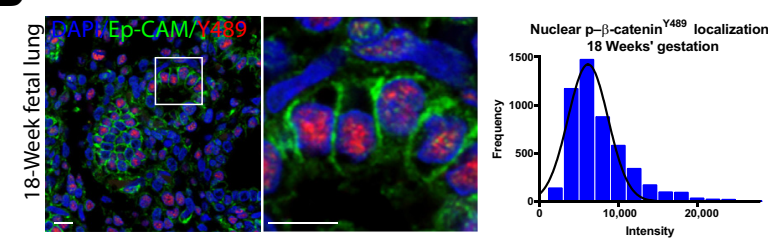

D
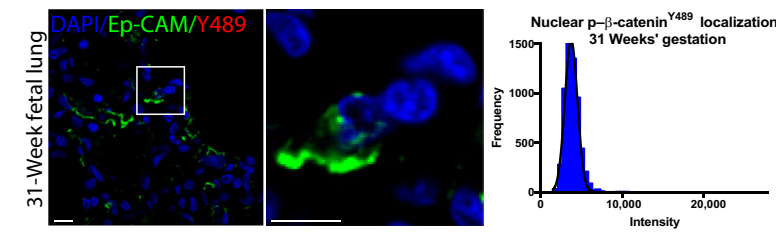

$\mathbf{F}$

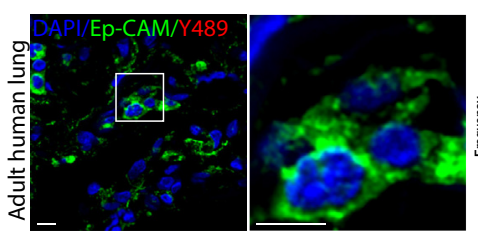

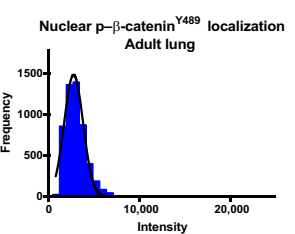

G

H

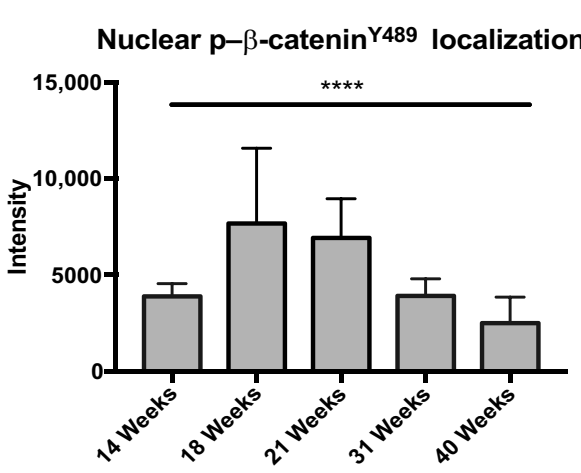

I

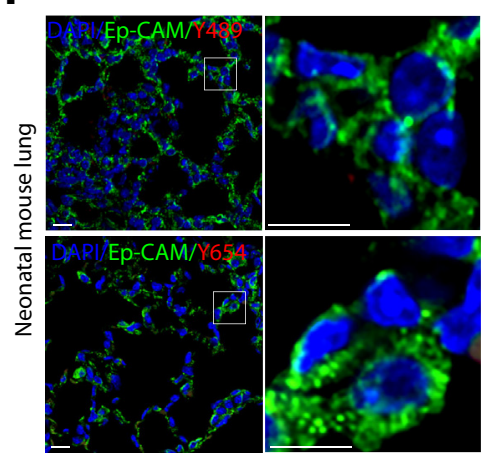

J
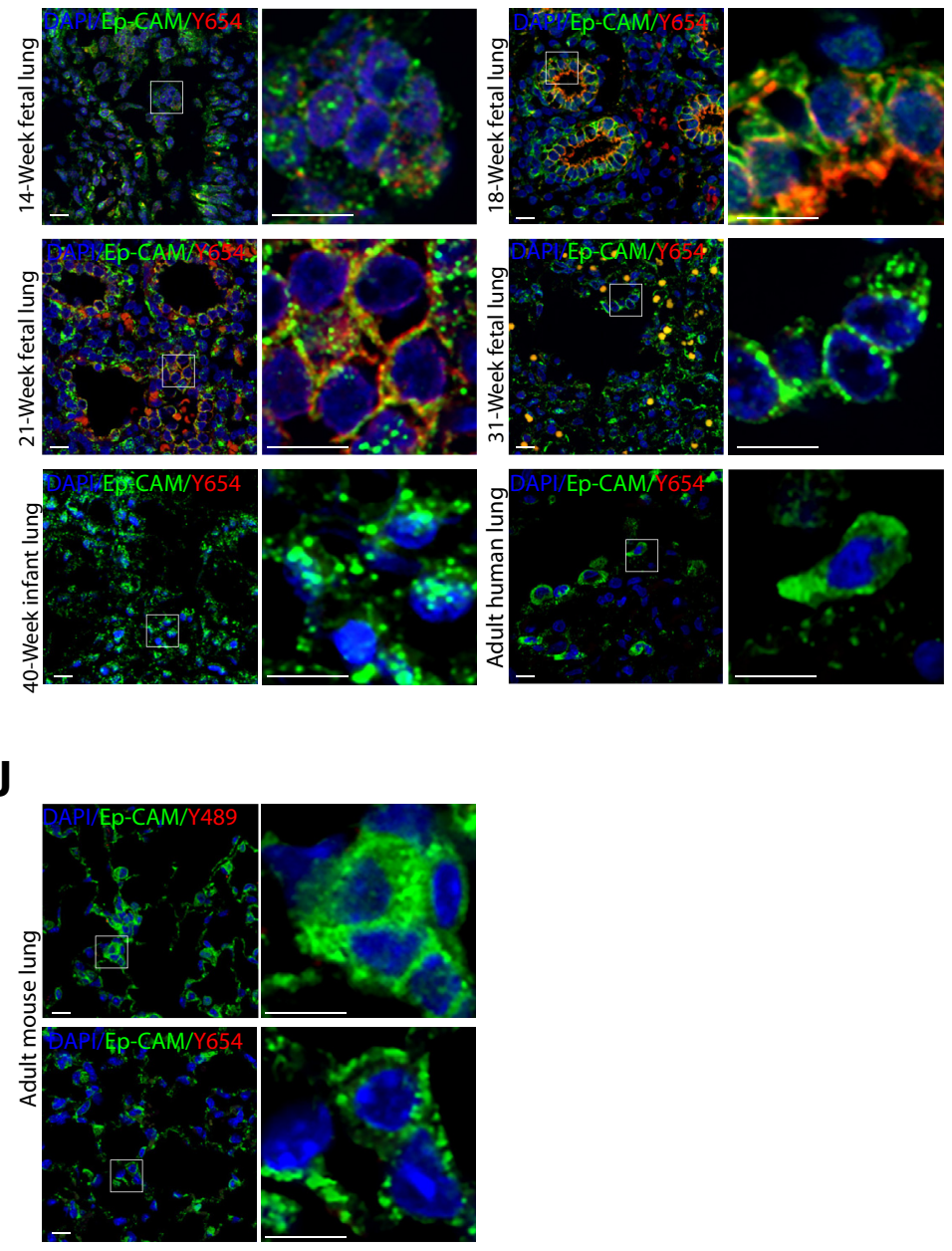
evidence to suggest that these disorders may share common pathogenic mechanisms; most notably, they show dysregulation of fundamental lung repair processes. Restoration of normal lung structure and function after injury relies on the transient reactivation of developmental pathways. ${ }^{3}$ In $\mathrm{BPD}$, environmental injury sustained during the vulnerable saccular or early alveolar stage of lung development results in an arrest of alveolarization, with fibrosis of the surrounding alveolar mesenchyme. ${ }^{4,5}$ Similarly, IPF is believed to be caused by repetitive injury to and dysfunction of the alveolar epithelium, leading to epithelial hyperplasia, fibroblast activation, and replacement of the alveolar space with collagen and extracellular matrix. ${ }^{1,6}$ Although the precise molecular mechanisms of both BPD and IPF remain elusive, there is growing evidence that the developmental pathways that play a role in injury repair may be responsible for the development of disease pathogenesis. ${ }^{7}$

Many developmental programs are necessary for lung organogenesis, and precise spatial and temporal coordination of Wnt signaling is critical for normal lung development and alveologenesis. ${ }^{8,9}$ Although phosphorylation of $\beta$-catenin at inhibitory sites at $\mathrm{N}$-terminal serine destruction sites is well characterized, prior studies have demonstrated that when Wnt signaling is active, $\beta$-catenin can also be phosphorylated at multiple different activating sites by tyrosine kinases and numerous other kinases. ${ }^{10}$ Phosphorylation at tyrosine $489\left(\mathrm{p}-\beta\right.$-catenin $\left.{ }^{\mathrm{Y} 489}\right)$ facilitates nuclear translocation of $\beta$-catenin, where interaction with the T-cell factor/lymphoid enhancer factor promoter initiates a program of transcription of downstream Wnt target genes. ${ }^{11}$ By contrast, $\beta$-catenin phosphorylated at tyrosine $654(\mathrm{p}-\beta$ catenin $^{\mathrm{Y} 654}$ ) remains localized to the cytoplasm and has been shown to activate Wnt signaling after additional phosphorylation events. ${ }^{12}$ In particular, $p-\beta$-catenin ${ }^{\text {Y654 }}$ interacts with other tyrosine kinases in response to reactive oxygen species and transforming growth factor- $\beta 1$ downstream effector phosphorylated Smad2, making it of particular interest in the Wnt response to lung injury. ${ }^{13}$

We have previously identified the importance of $\beta$ catenin phosphorylation in the fibroblastic changes associated with BPD, specifically the nuclear accumulation of $p-\beta$-cat-

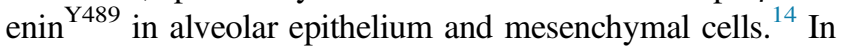
this study, archived fetal tissue was used to describe the normal trajectory of $\beta$-catenin phosphorylation at two activating tyrosine sites across lung organogenesis and alveologenesis from 14 weeks' gestation to term. Furthermore, it was shown that there is reemergence of a distinct midgestational signature of $\beta$-catenin phosphorylation at tyrosine 489 and 654 in lungs with BPD and IPF, accompanied by increased expression of Wnt target gene AXIN2. While Wnt signaling has been described in both disease processes, ${ }^{7}$ this study introduces a new paradigm for evaluating active Wnt signaling in BPD and IPF, opening the door for a shared therapeutic approach that targets the post-translational modification of $\beta$-catenin as a way to curb the dysregulated Wnt signaling that contributes to the pathophysiology of both diseases.

\section{Materials and Methods}

Approval for this research was obtained from the Vanderbilt Institutional Review Boards and other institutional review boards, as noted below.

\section{Human Lung Tissue}

The lungs of human infants who died with BPD from 2007 to 2015 , between 40 and 60 weeks' corrected gestational age $(n=5)$ and lungs from term stillborn infants (between 39 and 41 weeks' gestation) who died from nonrespiratory causes $(n=4)$ were obtained from the Translational Pathology Core Laboratory at the University of California, Los Angeles, with approval from the University of California, Los Angeles, Institutional Review Board. Formalin-fixed, paraffinembedded tissue sections were obtained from $\operatorname{IPF}(n=5)$ and chronic obstructive pulmonary disease (COPD; $n=3)$ lungs removed at the time of lung transplant. Control lung tissue was obtained from declined donor lungs $(n=5)$. Lung tissue was fixed in 10\% neutral-buffered formalin for 72 hours and then paraffin embedded. Diagnoses of IPF and COPD were made on the basis of consensus criteria. ${ }^{15,16}$ Adult lung samples were obtained with approval from the Vanderbilt University Institutional Review Board. Archived control fetal lung sections from formalin-fixed, paraffin-embedded sections from 14 to 31 weeks were obtained from the University of Washington, and sections from 18, 21, and 40 weeks were obtained from the University of California, Los Angeles.

\section{Animal Care and Bleomycin Experiments and Tissue Fixation}

C57BL/6 mice, aged 10 to 12 weeks, were administered a single dose of bleomycin (0.04 IU) by intratracheal instillation, and lung sections were inflation fixed in $10 \%$ buffered formalin and prepared as previously described. ${ }^{17-20}$ All mouse bleomycin experiments were approved by the Vanderbilt Institutional Animal Care and Use Committee.

Figure 1 Phosphorylated $Y 489 \beta$-catenin $\left(p-\beta\right.$-catenin ${ }^{Y 489}$ ) and phosphorylated $Y 654 \beta$-catenin $\left(p-\beta\right.$-catenin ${ }^{Y 654}$ ) localization in epithelial cells across lung development. A-F: Immunofluorescence (IF) for $p-\beta$-catenin ${ }^{\mathrm{Y} 489}$ (red) and at 14, 18, 21, 31, and 40 weeks, and in adult lung sections. Some $p-\beta$-catenin ${ }^{\mathrm{Y} 489}$ samples are also positive for epithelial cell adhesion molecule (Ep-CAM; green), with frequency of distribution curves (connecting line between means is shown in black) for intensity of $p-\beta$-catenin ${ }^{Y 489}$ staining. G: Mean intensity of $p-\beta$-catenin ${ }^{Y 489}$ staining by gestational age. One-way analysis of variance significant for differences between each group. H: IF for $p-\beta$-catenin ${ }^{\mathrm{Y} 654}$ (red) and at $14,18,21,31$, and 40 weeks, and in adult lung sections. $p-\beta$-catenin ${ }^{\mathrm{Y} 654}$ is exclusively present in EpCAM-positive cells (green). I and J: IF for $p-\beta$-catenin ${ }^{\text {Y } 489}$ (red) and $p-\beta$-catenin ${ }^{\text {Y654 }}$ (red) in neonatal and adult mouse lung sections shows almost no expression. Tiled images compiled as described. Boxed areas in left panels are shown in higher magnification in right panels $(\mathbf{A}-\mathbf{F}$ and $\mathbf{H}-\mathbf{J})$. Data are expressed as means \pm SD (G). ${ }^{* * *} P<0.0001$. Scale bar $=50 \mu \mathrm{m}(\mathbf{A}-\mathbf{F}$ and $\mathbf{H}-\mathbf{J})$. Original magnification, $\times 60(\mathbf{A}-\mathbf{F}$ and $\mathbf{H}-\mathbf{J})$. 
Animal Care and Hyperoxia Experiments and Tissue Fixation

C57BL/6 mice were exposed to $85 \% \mathrm{O}_{2}$ (hyperoxia) or air (normoxia) from postnatal day 2 until 14 days of age, as described previously. ${ }^{21,22}$ After hyperoxia exposure, lungs were inflation fixed with $10 \%$ buffered formalin and paraffin embedded. This protocol was approved by the Institutional Animal Care and Use Committee of the University of Alabama at Birmingham (Birmingham, AL) and was in compliance with the Public Health Services policy on humane care and use of laboratory animals.

\section{Immunofluorescence}

Immunofluorescence was performed as described previously. ${ }^{23-25}$ The following primary antibodies were used: anti-vimentin (bs-0756r; Bioss, Woburn, MA), anti-p- $\beta$-catenin $^{\text {Y489 }}$ (AB_10144551; Developmental Studies Hybridoma Bank, Iowa City, IA), ${ }^{11}$ anti- $-\mathrm{p}-\beta$-catenin ${ }^{\mathrm{Y} 654}$ (AB_1157889; Developmental Studies Hybridoma Bank), ${ }^{11}$ anti-epithelial cell adhesion molecule (Ep-CAM; ab71916; Abcam, Cambridge, MA), and anti-pro and mature surfactant protein B (ab40876; Abcam). Alexa-594and Alexa-488-conjugated secondary antibodies (Thermo Fisher Scientific, Waltham, MD) and counterstain DAPI (Vector Labs, Burlingame, CA) were also used.

\section{Immunoblot Assay for Antibody Validation}

A549 cells (ATCC, Manassas, VA), a human lung carcinoma cell line, were cultured on plastic in Ham's F12 media with L-glutamine and $10 \%$ fetal bovine serum to $80 \%$ confluency. Growth medium was removed and cells were incubated at $37^{\circ} \mathrm{C}$ in serum-free media for 2 hours. After serum starvation, cells were stimulated with $1 \mathrm{mmol} / \mathrm{L}$ pervanadate $(\mathrm{ECM}$ Biosciences, Versailles, KY) for 30 minutes. Cells were lysed with cold lysis buffer, and total protein was quantified using a bicinchoninic acid protein assay kit (Thermo Fisher Scientific). For dephosphorylation, alkaline phosphatase was used in accordance with the protocol provided by Abcam and described herein in detail: $30 \mathrm{~g}$ of each protein lysate was treated with calf intestinal alkaline phosphatase (CIP) in CIP buffer $(100 \mathrm{mmol} / \mathrm{L} \mathrm{NaCl}, 50 \mathrm{mmol} / \mathrm{L}$ Tris- $\mathrm{HCl}, 10 \mathrm{mmol} / \mathrm{L}$ $\mathrm{MgCl}_{2}, 1 \mathrm{mmol} / \mathrm{L}$ dithiothreitol, $\mathrm{pH}$ to 7.9 ) at $25^{\circ} \mathrm{C}$. $\mathrm{CIP}$ is provided as $10,000 \mathrm{U} / \mathrm{mL}$, and $1 \mathrm{U} / \mu \mathrm{g}$ protein was used, with incubation at $37^{\circ} \mathrm{C}$ for 60 minutes. Equal amounts of CIP-treated and untreated protein lysate were separated onto a polyacrylamide gel and transferred to a nitrocellulose membrane (Bio-Rad, Hercules, CA). After blocking with 5\% bovine serum albumin, membranes were incubated with primary and secondary antibodies, followed by chemiluminescence detection with SuperSignal West Pico Plus system (Thermo Fisher Scientific). Primary antibodies used were anti- $\beta$-catenin (ab32572; Abcam) and anti-p- $\beta$ catenin $^{\text {Y489 }}$ (AB_10144551; Developmental Studies
Hybridoma Bank). ${ }^{11}$ Blots were imaged with the ChemiDoc Touch Imaging System (Bio-Rad). Incubation with the $\mathrm{p}-\beta$-catenin ${ }^{\mathrm{Y} 489}$ monoclonal antibody demonstrated a single 90-kDa band (Supplemental Figure S1), and there was no band present in CIP-treated lysates.

\section{Confocal Microscopy and Histocytometry}

Immunofluoresence images were acquired on an automated TiE inverted fluorescence microscope platform equipped with an encoded motorized stage and Plan Apo $60 \times 1.40$ numerical aperture objective (Nikon Instruments, Inc., Melville, NY) and additionally outfitted with a Yokogawa X1 spinning disk head and Andor DU-897 EM-CCD. NIS-Elements software (versions 4.51 for image acquisition and 5.0 for image analysis; Nikon Instruments, Inc.) was used for both acquisition and assembly of the large image (stitched) montage as well as postacquisition image analysis. Briefly, image analysis proceeded with image segmentation of all nuclei, as defined by the intensity of the DAPI signal, and mean AF568 intensity was assessed within these predefined (nuclear) boundaries. Because of the automated large image array generation during acquisition, it was possible to analyze large cell populations within each experimental condition to ensure an accurate representation of each sample. As such, approximately 5000 nuclei were measured for each sample, and each sample was measured with an identical image segmentation and analysis routine. Mean intensity values were exported and plotted in Prism (Graphpad Software, Inc., La Jolla, CA) using frequency distribution analysis and subsequent curve fitting by gaussian-based nonlinear regression.

\section{RNA in Situ Hybridization}

RNAScope technology was used to perform all RNA in situ hybridization experiments. ${ }^{26}$ Paraffin-embedded sections from fetal lung, term newborn lung, BPD lung, IPF lung, COPD lung, and healthy adult lung were divided into sections $(5 \mu \mathrm{m}$ thick) and processed according to the instructions from ACD Bio (Newark, CA). The Axin2 probe was used (catalog number 400241).

\section{Statistical Analysis}

Analysis was performed on pooled data from all subjects before analysis. All values are reported as means, with error bars representing \pm SD. Statistical analysis was performed using Graphpad PRISM version 7. Frequency of distribution curves were generated, and nonlinear regression analysis was performed, with the use of two-tailed Welch's $t$-test for two-group comparisons and one-way analysis of variance for comparisons between multiple groups. For analysis of variance, the Tukey method was used to correct for multiple comparisons, and adjusted $P<0.05$ was considered statistically significant. 


\section{Results}

Post-Translational Modification of $\beta$-Catenin at Tyrosine 489 and 654 Is a Part of Normal Lung Development, with a Peak of Signaling in the Second Trimester

Representative lung tissue sections stained for $\mathrm{p}-$ $\beta$-catenin ${ }^{\text {Y489 }}$ from human fetuses at $14,18,21,31$, and

A

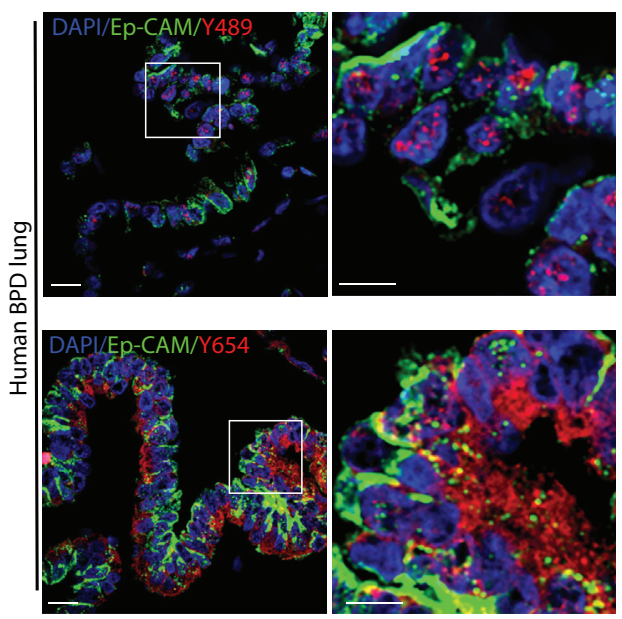

B
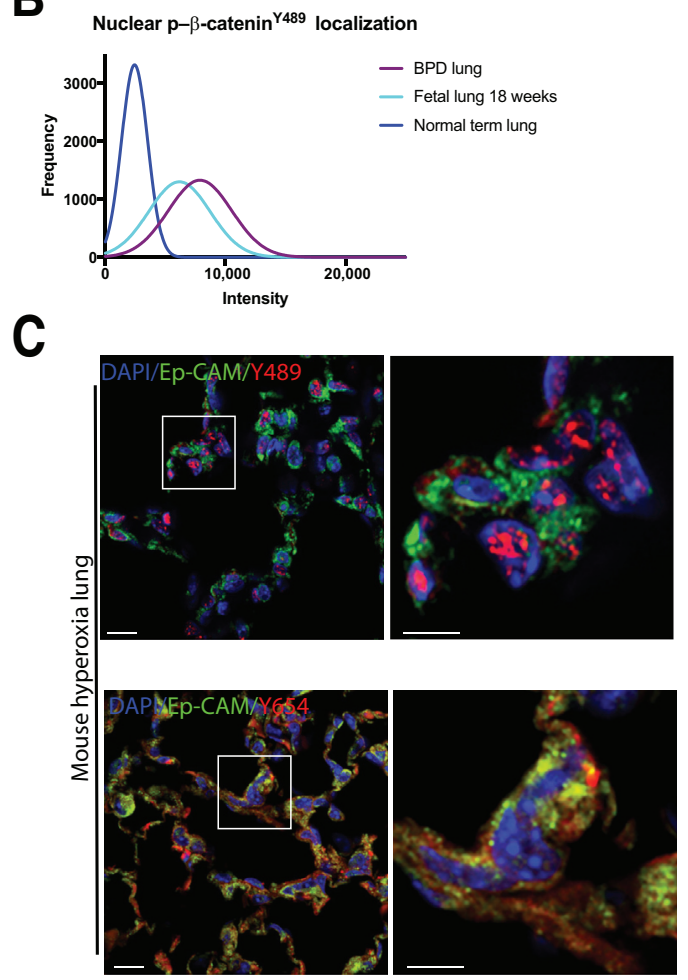

D

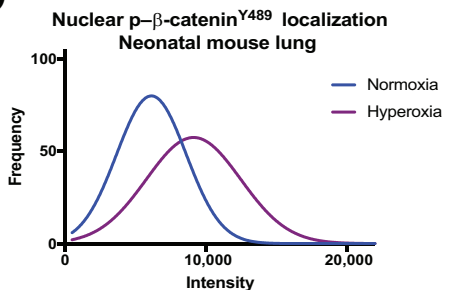

40 weeks, and adults are shown in Figure 1, A-F. Immunofluorescence was quantified to measure the intensity of nuclear $\mathrm{p}-\beta$-catenin ${ }^{\mathrm{Y} 489}$ staining. The greatest intensity of $p-\beta$-catenin ${ }^{\text {Y489 }}$ was observed in the 18 -week fetal specimens (Figure 1, B and G), with gradual decreases in intensity as gestational age increased (Figure 1, A-G). There was almost no nuclear $\mathrm{p}-\beta$-catenin ${ }^{\mathrm{Y} 489}$ by 40 weeks' gestation (Figure 1E), and this absence of nuclear $p-\beta$ catenin $^{\text {Y489 }}$ was also observed in healthy adult lung (Figure 1F). Although $\mathrm{p}-\beta$-catenin ${ }^{\mathrm{Y} 489}$ localizes to the nucleus, $p-\beta$-catenin ${ }^{\mathrm{Y} 654}$ localizes to the cytoplasm, where it can be phosphorylated at additional activated sites, and is an additional marker of Wnt activity. Y489 and Y654 p- $\beta$ catenin were restricted to distinct cellular lineages; the nuclei of both epithelial cells and surrounding cells were positive for $\mathrm{p}-\beta$-catenin ${ }^{\mathrm{Y} 489}$, but only the cells positive for Ep-CAM (CD326) were positive for cytoplasmic staining of $\mathrm{p}-\beta$-catenin ${ }^{\mathrm{Y} 654}$ (Figure $1 \mathrm{H}$ ). The staining of $\mathrm{p}-\beta$-cat$\operatorname{enin}^{\mathrm{Y} 654}$ also appeared the strongest at 18 weeks' gestation, with almost no detectable $\mathrm{p}-\beta$-catenin ${ }^{\mathrm{Y} 654}$ in the 40 weeks' gestation or healthy adult lungs. The relative absence of $\mathrm{p}-\beta$-catenin ${ }^{\mathrm{Y} 489}$ and $\mathrm{p}-\beta$-catenin ${ }^{\mathrm{Y} 654}$ in term neonates and adult lungs was consistent with what was seen in neonatal and adult mice (Figure 1, I and J). Together, these data suggest that these activated $p-\beta$-catenin forms play a role in regulating lung development in utero but are quiescent in postnatal life and during normal alveolar homeostasis.

BPD Lung Tissue and Neonatal Mouse Lung Tissue after Hyperoxia Exposure Both Demonstrate Nuclear $p-\beta$ Catenin $^{\text {Y489 }}$ and Epithelial Localization of Cytoplasmic $p-\beta$-Catenin ${ }^{\mathrm{Y} 654}$

Both $\mathrm{p}-\beta$-catenin ${ }^{\mathrm{Y} 489}$ and $\mathrm{p}-\beta$-catenin ${ }^{\mathrm{Y} 654}$ were present in BPD tissue, with the accumulation of $\mathrm{p}-\beta$-catenin ${ }^{\mathrm{Y} 654}$ being limited to the epithelial cellular compartment. $p-\beta$ Catenin $^{\mathrm{Y} 654}$ was only found in the cytoplasm of EpCAM-positive cells (Figure 2A). Morphometric analysis of

Figure 2 Phosphorylated $Y 489 \beta$-catenin $\left(p-\beta\right.$-catenin $\left.{ }^{\mathrm{Y} 489}\right)$ and phosphorylated $Y 654 \beta$-catenin $\left(p-\beta\right.$-catenin ${ }^{Y 654}$ ) localization in epithelial cells in human bronchopulmonary dysplasia (BPD) and in hyperoxia mouse model. A: Immunofluorescence (IF) for $p-\beta$-catenin ${ }^{\text {Y489 }}$ (red) and $p-\beta$-catenin ${ }^{\text {Y654 }}$ (red) in human infant lungs with BPD at term corrected gestational age, with epithelial cell adhesion molecule (Ep-CAM; green counterstain). Some Ep-CAM (green)-positive cells are also positive for $p-\beta$-catenin ${ }^{\text {Y } 489}$, and $p-\beta$-catenin ${ }^{Y 54}$ is exclusively present in Ep-CAM-positive cells. B: Frequency of distribution curves of histocytometry data demonstrates overlap between BPD and 18-week fetal lung, with these two populations of nuclei distinct from the nuclei in term infants when sorted for nuclear intensity of $p-\beta$-catenin ${ }^{\text {Y } 489}$ staining $(P<0.0001)$. C: IF for $p-\beta$-catenin ${ }^{\mathrm{Y} 489}$ (red) and $p-\beta$-catenin ${ }^{Y 654}$ (red) in neonatal mouse lungs exposed to hyperoxia from postnatal day 1 (PN1) to PN14. D: Frequency of distribution curves for quantitative IF for nuclear staining for $p-\beta$-catenin ${ }^{Y 489}$. Boxed areas in left panels are shown in higher magnification in right panels (A and $\mathbf{C})$. Twotailed $t$-test significant for differences between normoxia and hyperoxia exposed neonatal mice $(P<0.0001)$. Scale bar $=20 \mu \mathrm{m}(\mathbf{A}$ and $\mathbf{C})$. Original magnification, $\times 60(\mathbf{A}$ and $\mathbf{C})$. 
A

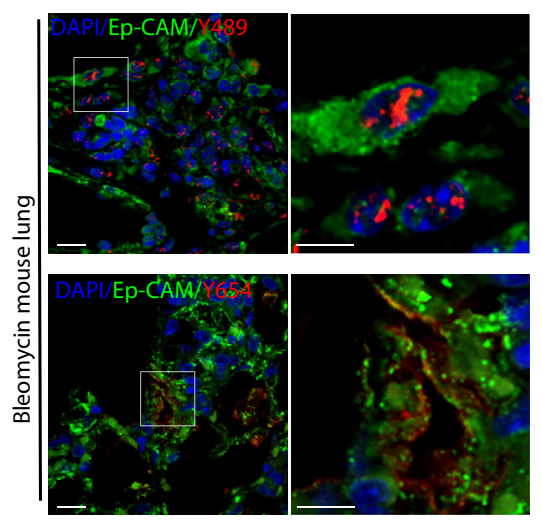

C
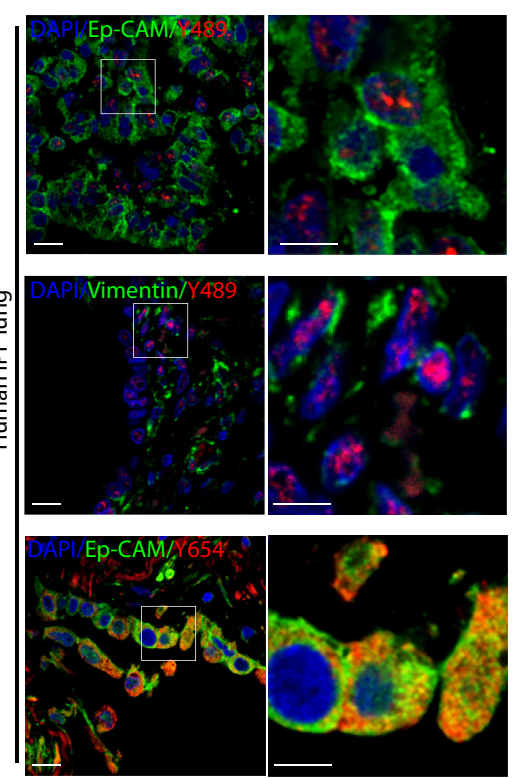
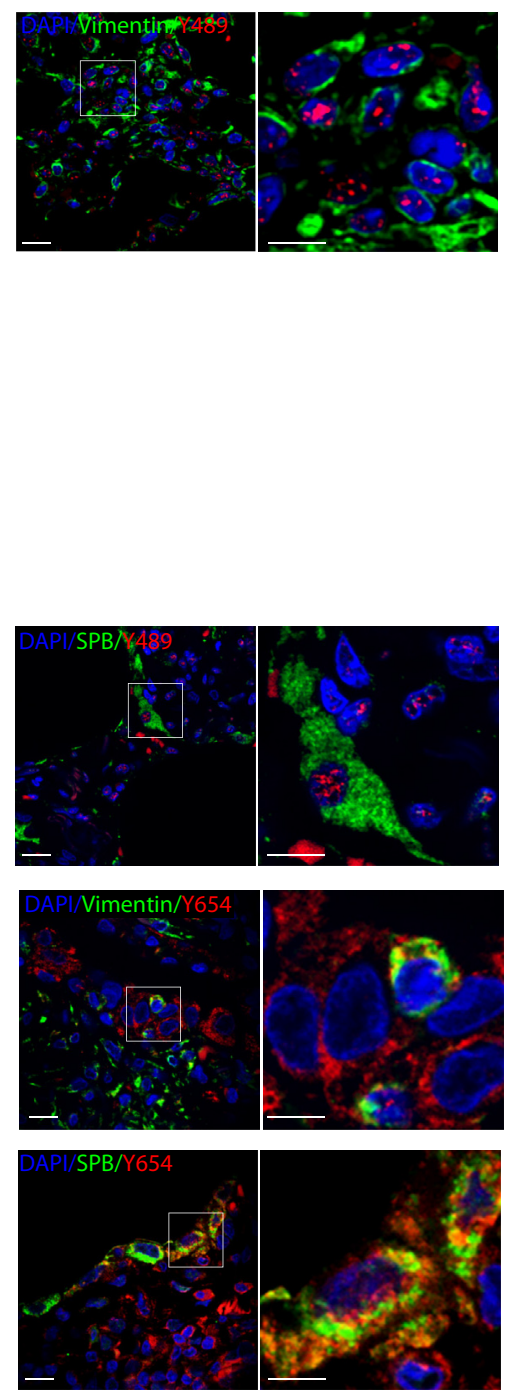

E
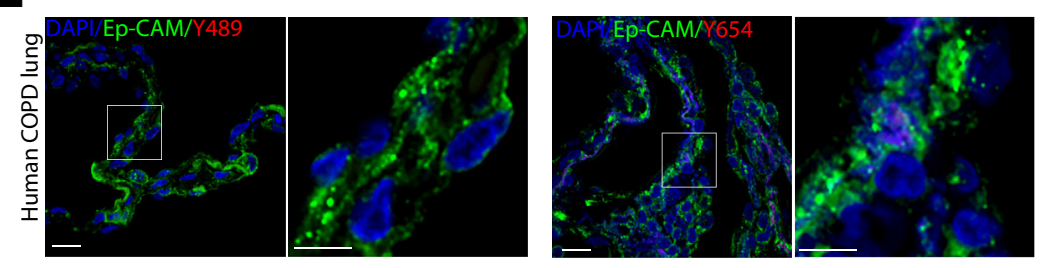

D

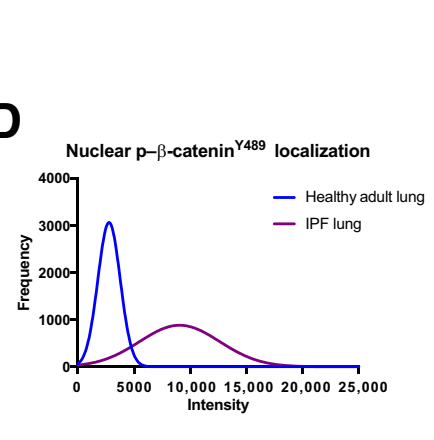

B

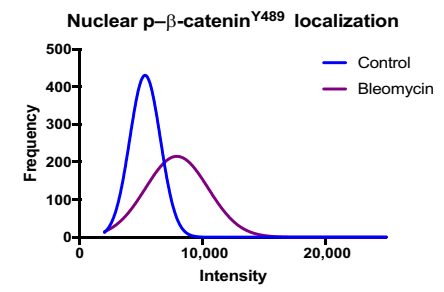

F

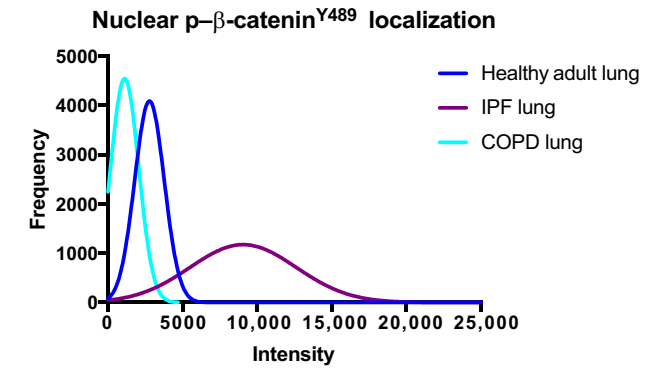


the microscopy images showed that when examined for the intensity of staining for nuclear $\mathrm{p}-\beta$-catenin ${ }^{\mathrm{Y} 489}$, the cells from human BPD tissue and fetal lung at 18 weeks segregated together, and these cells were distinct from the cells of normal term infants $(P<0.0001)$ (Figure $2 \mathrm{~B})$. Distribution of an increase in $\mathrm{p}-\beta$-catenin ${ }^{\mathrm{Y} 489}$ and $\mathrm{p}-\beta$-catenin ${ }^{\mathrm{Y} 654}$ was similar in a murine hyperoxia model of BPD when compared with lungs of neonatal mice who were grown in normoxic conditions (Figure 1I and Figure 2, C and D), with a similar pattern of quantification of nuclear $\mathrm{p}-\beta$ catenin $^{\text {Y489 }}$ in the mouse hyperoxia model $(P<0.001)$ (Figure 2D).

\section{IPF Lung Tissue and Mouse Fibrotic Lung Tissue}

after Bleomycin Injury Demonstrate Nuclear $p-\beta$-Catenin ${ }^{Y 489}$ and Epithelial Localization of Cytoplasmic $p-\beta$-Catenin ${ }^{\text {Y65 }}$

Recapitulation of developmental programs has been described in multiple models of injury and repair. It was unclear whether reactivation of a fetal program of phosphorylated $\beta$-catenin signaling would be found in the hyperplastic epithelium and hyperproliferative mesenchyme during a mouse model of lung injury repair. Costaining was, therefore, performed for phosphorylated $\beta$-catenin and lung lineage markers in normal mouse lungs and mice 21 days after administration of intratracheal bleomycin. In striking contrast to normal adult mouse lungs, there was nuclear localization of $\mathrm{p}-\beta$-catenin ${ }^{\mathrm{Y} 489}$ in both epithelial and mesenchymal cells (Figure 3A), most prominent in fibrotic areas. Morphometric quantification of the intensity of nuclear $\mathrm{p}-\beta$-catenin ${ }^{\mathrm{Y} 489}$ demonstrated distinct patterns of $\mathrm{p}-\beta$-catenin ${ }^{\mathrm{Y} 489}$ between the control and bleomycinexposed mice $(P<0.001)$ (Figure 3B). Epithelial cells, identified by expression of Ep-CAM (CD326) accumulated $\mathrm{p}-\beta$-catenin ${ }^{\mathrm{Y} 489}$ in their nuclei, as did vimentin-positive mesenchymal cells (Figure 3A). There was also widespread cytoplasmic $\mathrm{p}-\beta$-catenin ${ }^{\mathrm{Y} 654}$ restricted to epithelial cells in bleomycin-treated lung, analogous to what was observed in 18- to 21-week gestational lungs in humans (Figure $1 \mathrm{H}$ and $3 \mathrm{~A}$ ). Recognizing this pattern of increased phosphorylated $\beta$-catenin (when compared with control adult mice) in an experimental model of lung fibrosis, it was then investigated whether this pattern would be observed in lungs from patients with IPF. As in bleomycin-treated mice, widespread nuclear $\mathrm{p}-\beta$-catenin ${ }^{\mathrm{Y} 489}$ was found in epithelial cells (positive for Ep-CAM and pro-surfactant protein B) and vimentin-positive mesenchymal cells, as well as epithelial-restricted $\mathrm{p}-\beta$-catenin ${ }^{\mathrm{Y} 654}$ (Figure $3 \mathrm{C}$ ). In contrast, neither Y489 nor Y654 phosphorylated $\beta$-catenin was seen in lungs from patients with COPD (Figure 3E). Comparing the intensity of nuclear $p-\beta$-catenin ${ }^{\mathrm{Y} 89}$ in lungs from healthy adult lungs, COPD lungs, and IPF lungs demonstrates clear differences between these patients, with the IPF lung having a pattern of nuclear $p-\beta$-catenin ${ }^{\text {Y489 }}$ that is distinct from either COPD or normal adult lungs $(P<0.0001)$ (Figure $1 \mathrm{H}$ and Figure 3, C, E, and $\mathrm{F}$ ). Together, these data suggest that a fetal pattern of phosphorylated $\beta$-catenin reemerges during lung injury repair and that abnormal persistence of this program is active in chronic fibroproliferative, but not destructive, adult lung disease.

\section{BPD Lung Tissue and IPF Tissue Exhibit a Similar Pattern of Nuclear $p-\beta$-Catenin ${ }^{\text {Y489 }}$ and Cytoplasmic $p-\beta$-Catenin ${ }^{Y 654}$ that Strongly Resembles the Expression Pattern Seen in Second-Trimester Fetal Lung}

Analysis of $>5000$ nuclei per condition demonstrated that there were no significant differences between BPD lung tissues and IPF lung tissues (Figure 3G). Furthermore, the intensity of nuclear staining $\mathrm{p}-\beta$-catenin ${ }^{\mathrm{Y} 489}$ in samples from both BPD and IPF was visually and statistically indistinguishable from that of second-trimester fetal lung (Figure 2A and Figure 3, C and G). Quantitative immunofluorescence shows that the intensity of $\mathrm{p}-\beta$-catenin ${ }^{\mathrm{Y} 489}$ staining of $\mathrm{BPD}$, IPF, and second-trimester fetal lung was markedly increased compared with the term infant lung and adult lung (Figure 2B and Figure 3, D and G).

\section{Expression of Downstream Wnt Target Gene AXIN2 Correlates with the Presence of Nuclear $p-\beta$-Catenin ${ }^{\text {Y } 489}$}

AXIN2 is a member of the $\beta$-catenin destruction complex, and expression of AXIN2 is used widely as a marker of Wnt responsiveness. ${ }^{27}$ To determine whether the observed pattern of phosphorylated $\beta$-catenin was of functional significance, RNA in situ hybridization was performed to

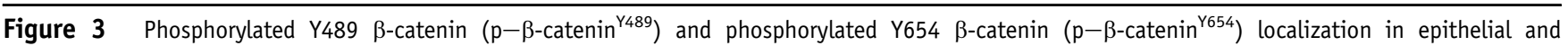
mesenchymal cells in human idiopathic pulmonary fibrosis (IPF), bleomycin mouse model, and human chronic obstructive pulmonary disease (COPD). A: Immunofluorescence (IF) for $p-\beta$-cateni ${ }^{\mathrm{Y} 489}$ (red) and $p-\beta$-cateni ${ }^{\mathrm{Y} 654}$ (red) in mouse lungs after treatment with bleomycin B: Frequency of distribution curves for quantitative IF for nuclear staining for $p-\beta$-catenin ${ }^{Y 489}$. Two-tailed $t$-test significant for differences between IPF and normal lung tissue $(P<0.0001)$. C: IF for $p-\beta$-catenin ${ }^{\text {Y489 }}$ (red) and $p-\beta$-catenin ${ }^{\mathrm{Y} 54}$ (red) in IPF lung tissue, with some $p-\beta$-catenin ${ }^{\text {Y489 }}$. Some $p-\beta$-catenin ${ }^{\text {Y489 }}$ is also positive for vimentin, pro-surfactant protein B (pro-SPB), and epithelial cell adhesion molecule (Ep-CAM) (counterstains in green). $p-\beta$-Catenin ${ }^{\mathrm{Y} 654}$ expression is limited to epithelial cells expressing pro-SPB or Ep-CAM. D: Frequency of distribution curves for quantitative IF for nuclear staining for $p-\beta$-catenin ${ }^{\text {Y489 }}$. E: IF for $p-\beta$-catenin ${ }^{Y 489}$ (red) and $p-\beta$-catenin ${ }^{Y 654}$ (red) in COPD lung tissue. F: Frequency of distribution curves for quantitative IF for intensity of nuclear staining for $p-\beta$-catenin ${ }^{Y 489}$ in normal adult lung, IPF lung, and COPD lung. One-way analysis of variance significant for differences between normal adult lung, COPD lung, and IPF lung nuclei $(P<0.0001)$. G: Frequency of distribution curves for histocytometry for intensity of nuclear staining for $p-\beta$-catenin ${ }^{\text {Y489 }}$ in 18 weeks' fetal lung, bronchopulmonary dysplasia (BPD) lung, and IPF lung, showing significant overlap between the groups $(P>0.1)$. Boxed areas in left panels are shown in higher magnification in right panels $(\mathbf{A}, \mathbf{C}$, and $\mathbf{E})$. Scale bar $=20 \mu \mathrm{m}(\mathbf{A}, \mathbf{C}$, and $\mathbf{E})$. Original magnification, $\times 60(\mathbf{A}, \mathbf{C}$, and $\mathbf{E})$.
} 
A
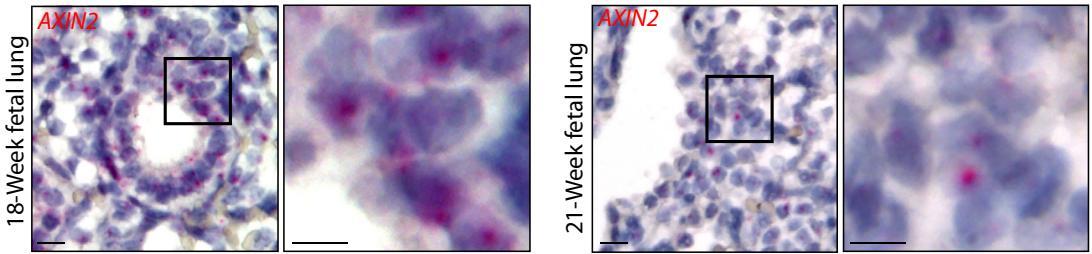

Figure 4 RNA in situ hybridization for AXIN2 expression in fetal lung, bronchopulmonary dysplasia (BPD) lung, idiopathic pulmonary fibrosis (IPF) lung, and healthy infant and adult controls using RNAscope. A: AXIN2 expression in human fetal, infant, and adult lung sections (red). B: AXIN2 expression in BPD and IPF tissue (red). C: Quantification
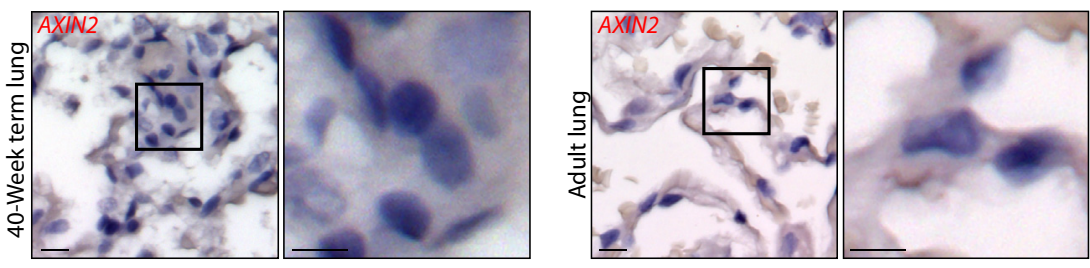
of AXIN2 expression, normalized per thousand cells counted. There are significant differences between BPD and term infants and IPF and healthy adults. Data are expressed as means \pm SD (C). Boxed areas in left panels are shown in higher magnification in right panels ( $A$ and B). ${ }^{*} P<0.01$. Scale bar $=20 \mu \mathrm{m}(\mathbf{A}$ and $\mathbf{B})$. Original magnification, $\times 60$ (A and $\mathbf{B})$.

B
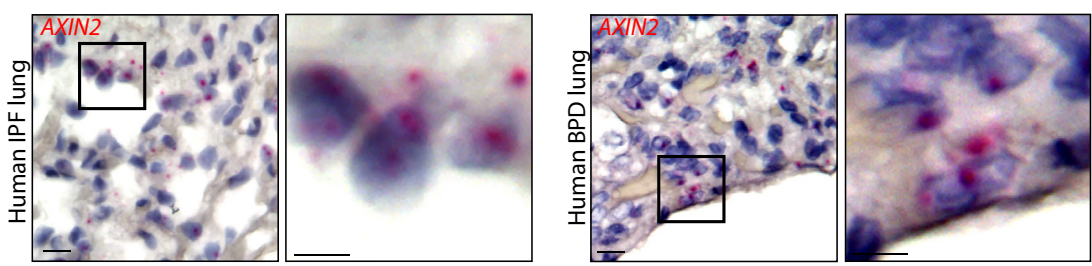

C

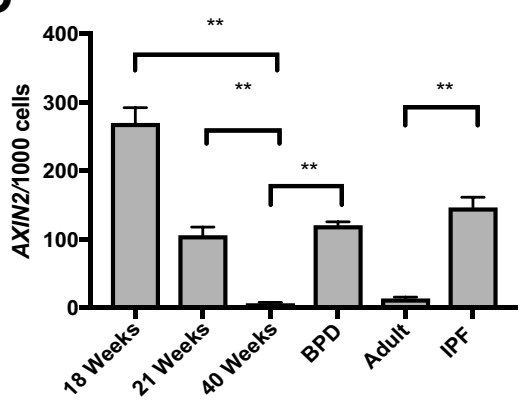

look for expression of AXIN2. AXIN2 expression was noted in 18-week fetal lung, with a slight decrease in expression in 21-week fetal lung (Figure 4A). Although BPD and IPF lung showed AXIN2 expression in alveolar tissue, there was no AXIN2 expression observed in the healthy lungs of term infants or adults (Figure 4, A and B). Quantification of these data showed significant increase in AXIN2 expression in BPD and IPF lung tissue compared with healthy term infant lung and healthy adult lung, respectively $(P<0.01)$ (Figure $4 \mathrm{C})$.

\section{Discussion}

$\beta$-Catenin phosphorylation is an important modulator of Wnt signaling. Phosphorylation of $\beta$-catenin at tyrosine 489 promotes nuclear localization and transcription of Wnt target genes and has been previously reported to play a role in the fibroblastic changes associated with BPD. ${ }^{14}$ In contrast, phosphorylation of $\beta$-catenin at other tyrosine sites, such as Y654, causes it to dissociate from E-cadherin and interact with other signaling complexes within the cell. ${ }^{28}$ In particular, $\mathrm{p}-\beta$-catenin ${ }^{\mathrm{Y} 654}$ is involved with transforming growth factor- $\beta 1$ signaling to promote epithelialmesenchymal transition. ${ }^{13}$ Nuclear $\mathrm{p}-\beta$-catenin ${ }^{\mathrm{Y} 489}$ colocalizes with mesenchymal markers vimentin and plateletderived growth factor receptor $\alpha$ in BPD. ${ }^{14}$ Given the association of $\mathrm{p}-\beta$-catenin ${ }^{\mathrm{Y} 654}$ with transforming growth factor- $\beta 1$ and $p-\beta$-catenin ${ }^{\mathrm{Y} 489}$ with the fibrosis in $\mathrm{BPD}$, this study sought to characterize the pattern of these two forms of $\beta$-catenin in normal lung development and in fibrotic lung disease.

This study defined the developmental course of these two forms of phosphorylated $\beta$-catenin, demonstrating that this program peaks in mid-second trimester and is quiescent by term and through adulthood. This study shows that this midgestational program is active after experimental injury that occurs during the neonatal period or adulthood. Furthermore, BPD and IPF lungs have a similar signature of nuclear accumulation of $\mathrm{p}-\beta$-catenin ${ }^{\mathrm{Y} 489}$ and cytoplasmic accumulation of $p-\beta$-catenin ${ }^{\mathrm{Y} 654}$ in the alveolar epithelium; this signature has strong homology with the distribution of phosphorylated $\beta$-catenin in second-trimester fetal lung, and this signature of phosphorylation is associated with evidence of downstream active canonical Wnt signaling.

Tight regulation of the spatial and temporal events in Wnt signaling may be crucial for effective lung epithelial repair. Reactivation of fetal Wnt signaling pathways may play an important role in the repair and regeneration of the lung epithelium in diseases, including BPD, IPF, and others; however, an excess of (or failure to adaptively down-regulate) Wnt signaling in the alveolar epithelium and surrounding mesenchyme may cause pathologic fibrotic tissue remodeling. Notably, this signature of phosphorylated $\beta$-catenin observed in this study is not a nonspecific response to lung injury, because there was little 
phosphorylated $\beta$-catenin present in lungs with COPD. This is consistent with prior work in COPD that showed a decrease in activated Wnt signaling that accompanied this disease process. ${ }^{7,29}$ In the case of BPD, the injury to the lung occurs during the saccular stage of lung development, just after the peak of Wnt signaling in the second trimester. The mechanisms whereby persistence or reactivation of Wnt signaling during the saccular stage leads to phenotype of decreased alveolarization and fibrosis in BPD and whereby increased Wnt signaling after repetitive injury leads to type 2 alveolar cell hyperplasia and fibrosis in IPF remain undefined but may represent different developmental sensitivities of the lung epithelium to these signals.

This study has some notable limitations. Autopsy tissue from infants who died with BPD and from adults whose IPF was treated with lung transplantation represents the most severe form of these diseases and, therefore, may not be representative of milder or early pathology. In the case of $\mathrm{BPD}$, there has been a distinction made between the old and new forms of the disease, ${ }^{2}$ with the newer form of the disease being described as having less significant fibrosis as a result of clinical innovations in antenatal steroid use, administration of surfactant, and gentle ventilation techniques; however, there is a growing appreciation that in the most severe form, even the new BPD has features of fibrosis at the alveolar septa. ${ }^{30}$ We have previously found markers of mesenchymal proliferation and fibrosis in infants who have died with BPD in the past 10 years, suggesting that fibrosis remains a feature of BPD. ${ }^{25}$

Although the nature of this study is limited to demonstrating a correlation between phosphorylated $\beta$-catenin and fibrotic lung disease, these results suggest that severe BPD and end-stage IPF are associated with a similar pattern of $\beta$-catenin phosphorylation. Both BPD and IPF are thought to result from complex interactions between a variety of genetic polymorphisms and the environment, and these data are consistent with other work demonstrating a role for the Wnt signaling in the pathology of both diseases. A recent whole exome sequencing study of genomic DNA from neonatal blood spots showed rare conserved variants in the Wnt signaling pathway in infants with BPD. ${ }^{31}$ Although several genes in other pathways, such as telomere maintenance, have been identified in familial IPF, ${ }^{6}$ increased functional Wnt signaling has also been seen in sporadic IPF. ${ }^{32}$ It is possible that individuals with genetic polymorphisms in the regulation of Wnt signaling are more likely to develop BPD when challenged with the environmental stresses that accompany preterm birth. Preterm infants with these polymorphisms and IPF patients with Wnt-responsive fibrosis may benefit from therapeutics that target this signaling pathway.

Activated Wnt signaling has been extensively described in multiple different solid organ cancers, and there are active clinical trials for small molecules that target different aspects of the Wnt pathway. There are also multiple selective tyrosine kinase inhibitors that may be repurposed to block the posttranslational phosphorylation of $\beta$-catenin at Y489 and Y654 in BPD or IPF, and future studies in mouse models of BPD and IPF may use these inhibitors to determine whether there is a causal link between $\beta$-catenin phosphorylation and disease pathology. The signature of nuclear $\mathrm{p}-\beta$-catenin ${ }^{\mathrm{Y} 489}$ and cytoplasmic $\mathrm{p}-\beta$-catenin ${ }^{\mathrm{Y} 654}$ was recapitulated in murine models of BPD and IPF, and there is some work that suggests that using dasatanib, an Src-kinase inhibitor, attenuated bleomycin-induced pulmonary fibrosis in mice. ${ }^{33}$ Dasatinib has also been shown to decrease the fibroblastic changes associated with BPD in an in vitro model and to decrease the nuclear localization of $\mathrm{p}-\beta$-catenin ${ }^{\mathrm{Y} 489}{ }^{14}$

Because Wnt signaling is involved in multiple organ processes during normal development, there have been multiple concerns raised about the safety of targeting the Wnt pathway as a therapeutic strategy. ${ }^{32}$ These data suggest that one possible approach would be to target the particular processes involved in the post-translational phosphorylation of $\beta$-catenin in a manner that restricts the delivery of the drug to the alveolar spaces of the lung to stop the progression of fibrotic lung disease in both neonates born prematurely and in adults with progressive IPF. Targeting the Wnt pathway in this way may provide a novel strategy to restore lung health after injury.

\section{Acknowledgments}

We thank the Developmental Studies Hybridoma Bank for the phosphorylated $\beta$-catenin-Y489 and $\beta$-catenin-Y654 antibodies developed by Janne Balsamo and Jack Lilien, which were generated by the Eunice Kennedy Shriver National Institute of Child Health and Human Development of the NIH at the University of Iowa.

\section{Supplemental Data}

Supplemental material for this article can be found at https://doi.org/10.1016/j.ajpath.2017.12.004.

\section{References}

1. Richeldi L, Collard HR, Jones MG: Idiopathic pulmonary fibrosis. Lancet 2017, 389:1941-1952

2. Jobe AH: The new bronchopulmonary dysplasia. Curr Opin Pediatr 2011, 23:167-172

3. Beers MF, Morrisey EE: The three R's of lung health and disease: repair, remodeling, and regeneration. J Clin Invest 2011, 121:2065-2073

4. Baraldi E, Filippone M: Chronic lung disease after premature birth. N Engl J Med 2007, 357:1946-1955

5. Hadchouel A, Franco-Montoya ML, Delacourt C: Altered lung development in bronchopulmonary dysplasia. Birth Defects Res A Clin Mol Teratol 2014, 100:158-167

6. Kropski JA, Blackwell TS, Loyd JE: The genetic basis of idiopathic pulmonary fibrosis. Eur Respir J 2015, 45:1717-1727

7. Ota C, Baarsma HA, Wagner DE, Hilgendorff A, Konigshoff M: Linking bronchopulmonary dysplasia to adult chronic lung diseases: role of WNT signaling. Mol Cell Pediatr 2016, 3:34

8. Frank DB, Peng T, Zepp JA, Snitow M, Vincent TL, Penkala IJ, Cui Z, Herriges MJ, Morley MP, Zhou S, Lu MM, Morrisey EE: Emergence 
of a wave of Wnt signaling that regulates lung alveologenesis by controlling epithelial self-renewal and differentiation. Cell Rep 2016, $17: 2312-2325$

9. Zhang M, Shi J, Huang Y, Lai L: Expression of canonical WNT/betaCATENIN signaling components in the developing human lung. BMC Dev Biol 2012, 12:21

10. Verheyen EM, Gottardi CJ: Regulation of Wnt/beta-catenin signaling by protein kinases. Dev Dyn 2010, 239:34-44

11. Rhee J, Buchan T, Zukerberg L, Lilien J, Balsamo J: Cables links Robo-bound Abl kinase to N-cadherin-bound beta-catenin to mediate Slit-induced modulation of adhesion and transcription. Nat Cell Biol 2007, 9:883-892

12. van Veelen W, Le NH, Helvensteijn W, Blonden L, Theeuwes M, Bakker ER, Franken PF, van Gurp L, Meijlink F, van der Valk MA, Kuipers EJ, Fodde R, Smits R: beta-Catenin tyrosine 654 phosphorylation increases Wnt signalling and intestinal tumorigenesis. Gut 2011, 60:1204-1212

13. Xi Y, Wei Y, Sennino B, Ulsamer A, Kwan I, Brumwell AN, Tan K, Aghi MK, McDonald DM, Jablons DM, Chapman HA: Identification of pY654-beta-catenin as a critical co-factor in hypoxia-inducible factor-1alpha signaling and tumor responses to hypoxia. Oncogene 2013, 32:5048-5057

14. Sucre JM, Vijayaraj P, Aros CJ, Wilkinson D, Paul M, Dunn B, Guttentag SH, Gomperts BN: Posttranslational modification of betacatenin is associated with pathogenic fibroblastic changes in bronchopulmonary dysplasia. Am J Physiol Lung Cell Mol Physiol 2017, 312:L186-L195

15. Raghu G, Collard HR, Egan JJ, Martinez FJ, Behr J, Brown KK, Colby TV, Cordier JF, Flaherty KR, Lasky JA, Lynch DA, Ryu JH, Swigris JJ, Wells AU, Ancochea J, Bouros D, Carvalho C, Costabel U, Ebina M, Hansell DM, Johkoh T, Kim DS, King TE Jr, Kondoh Y, Myers J, Muller NL, Nicholson AG, Richeldi L, Selman M, Dudden RF, Griss BS, Protzko SL, Schunemann HJ: An official ATS/ERS/JRS/ALAT statement: idiopathic pulmonary fibrosis: evidence-based guidelines for diagnosis and management. Am J Respir Crit Care Med 2011, 183:788-824

16. Qaseem A, Wilt TJ, Weinberger SE, Hanania NA, Criner G, van der Molen T, Marciniuk DD, Denberg T, Schunemann H, Wedzicha W, MacDonald R, Shekelle P: Diagnosis and management of stable chronic obstructive pulmonary disease: a clinical practice guideline update from the American College of Physicians, American College of Chest Physicians, American Thoracic Society, and European Respiratory Society. Ann Intern Med 2011, 155:179-191

17. Degryse AL, Tanjore $\mathrm{H}, \mathrm{Xu} \mathrm{XC}$, Polosukhin VV, Jones BR, McMahon FB, Gleaves LA, Blackwell TS, Lawson WE: Repetitive intratracheal bleomycin models several features of idiopathic pulmonary fibrosis. Am J Physiol Lung Cell Mol Physiol 2010, 299:L442-L452

18. Lawson WE, Cheng DS, Degryse AL, Tanjore H, Polosukhin VV, Xu XC, Newcomb DC, Jones BR, Roldan J, Lane KB, Morrisey EE, Beers MF, Yull FE, Blackwell TS: Endoplasmic reticulum stress enhances fibrotic remodeling in the lungs. Proc Natl Acad Sci U S A 2011, 108:10562-10567

19. Degryse AL, Xu XC, Newman JL, Mitchell DB, Tanjore H, Polosukhin VV, Jones BR, McMahon FB, Gleaves LA, Phillips JA 3rd, Cogan JD, Blackwell TS, Lawson WE: Telomerase deficiency does not alter bleomycin-induced fibrosis in mice. Exp Lung Res 2012, 38:124-134
20. Tanjore H, Degryse AL, Crossno PF, Xu XC, McConaha ME, Jones BR, Polosukhin VV, Bryant AJ, Cheng DS, Newcomb DC, McMahon FB, Gleaves LA, Blackwell TS, Lawson WE: beta-Catenin in the alveolar epithelium protects from lung fibrosis after intratracheal bleomycin. Am J Respir Crit Care Med 2013, 187:630-639

21. Ramani M, Bradley WE, Dell'Italia LJ, Ambalavanan N: Early exposure to hyperoxia or hypoxia adversely impacts cardiopulmonary development. Am J Respir Cell Mol Biol 2015, 52: 594-602

22. Ambalavanan N, Nicola T, Hagood J, Bulger A, Serra R, MurphyUllrich J, Oparil S, Chen YF: Transforming growth factor-beta signaling mediates hypoxia-induced pulmonary arterial remodeling and inhibition of alveolar development in newborn mouse lung. Am J Physiol Lung Cell Mol Physiol 2008, 295:L86-L95

23. Paul MK, Bisht B, Darmawan DO, Chiou R, Ha VL, Wallace WD, Chon AT, Hegab AE, Grogan T, Elashoff DA, Alva-Ornelas JA, Gomperts BN: Dynamic changes in intracellular ROS levels regulate airway basal stem cell homeostasis through Nrf2-dependent Notch signaling. Cell Stem Cell 2014, 15:199-214

24. Wilkinson DC, Alva-Ornelas JA, Sucre JM, Vijayaraj P, Durra A, Richardson W, Jonas SJ, Paul MK, Karumbayaram S, Dunn B, Gomperts BN: Development of a three-dimensional bioengineering technology to generate lung tissue for personalized disease modeling. Stem Cells Transl Med 2016, 6:622-633

25. Sucre JM, Wilkinson D, Vijayaraj P, Paul M, Dunn B, AlvaOrnelas JA, Gomperts BN: A three-dimensional human model of the fibroblast activation that accompanies bronchopulmonary dysplasia identifies Notch-mediated pathophysiology. Am J Physiol Lung Cell Mol Physiol 2016, 310:L889-L898

26. Wang F, Flanagan J, Su N, Wang LC, Bui S, Nielson A, Wu X, Vo HT, Ma XJ, Luo Y: RNAscope: a novel in situ RNA analysis platform for formalin-fixed, paraffin-embedded tissues. J Mol Diagn 2012, 14:22-29

27. Li N, Yousefi M, Nakauka-Ddamba A, Tobias JW, Jensen ST, Morrisey EE, Lengner CJ: Heterogeneity in readouts of canonical wnt pathway activity within intestinal crypts. Dev Dyn 2016, 245:822-833

28. Lilien J, Balsamo J: The regulation of cadherin-mediated adhesion by tyrosine phosphorylation/dephosphorylation of beta-catenin. Curr Opin Cell Biol 2005, 17:459-465

29. Baarsma HA, Skronska-Wasek W, Mutze K, Ciolek F, Wagner DE, John-Schuster G, Heinzelmann K, Gunther A, Bracke KR, Dagouassat M, Boczkowski J, Brusselle GG, Smits R, Eickelberg O, Yildirim AO, Konigshoff M: Noncanonical WNT-5A signaling impairs endogenous lung repair in COPD. J Exp Med 2017, 214:143-163

30. Voynow JA: "New" bronchopulmonary dysplasia and chronic lung disease. Paediatr Respir Rev 2017, 24:17-18

31. Li J, Yu KH, Oehlert J, Jeliffe-Pawlowski LL, Gould JB, Stevenson DK, Snyder M, Shaw GM, O'Brodovich HM: Exome sequencing of neonatal blood spots and the identification of genes implicated in bronchopulmonary dysplasia. Am J Respir Crit Care Med 2015, 192:589-596

32. Konigshoff M, Balsara N, Pfaff EM, Kramer M, Chrobak I, Seeger W, Eickelberg O: Functional Wnt signaling is increased in idiopathic pulmonary fibrosis. PLoS One 2008, 3:e2142

33. Yilmaz O, Oztay F, Kayalar O: Dasatinib attenuated bleomycin-induced pulmonary fibrosis in mice. Growth Factors 2015, 33:366-375 